\title{
TNF-a differentially modulates the level of subunits of respiratory electron transport complexes of ER/PR +ve/-ve breast cancer cells to regulate mitochondrial complex activity and tumorigenic potential
}

Anjali Shinde

The Maharaja Sayajirao University of Baroda

HyeRyeon Jung

Seoul National University

Hayun Lee

Seoul National University

Kritarth Singh

University College London

Milton Roy

The Maharaja Sayajirao University of Baroda

Dhruv Gohel

The Maharaja Sayajirao University of Baroda

Han Byeol Kim

Seoul National University

Minal Mane

The Maharaja Sayajirao University of Baroda

Hitesh Vasiyani

The Maharaja Sayajirao University of Baroda

Fatema Currim

The Maharaja Sayajirao University of Baroda

\section{Yuri Seo}

Seoul National University of Baroda

\section{Seojin Yang}

Seoul National University

\section{Eugene C Yi}

Seoul National University

Singh Rajesh ( $\nabla$ singhraj1975@gmail.com )

The Maharaja Sayajirao University of Baroda https://orcid.org/0000-0002-4986-3486 
Research

Keywords: Breast cancer heterogeneity, TNF-a, mitochondria, metabolism, inflammation

Posted Date: October 9th, 2020

DOl: https://doi.org/10.21203/rs.3.rs-87274/v1

License: (c) (i) This work is licensed under a Creative Commons Attribution 4.0 International License. Read Full License

Version of Record: A version of this preprint was published at Cancer \& Metabolism on April 29th, 2021. See the published version at https://doi.org/10.1186/s40170-021-00254-9. 


\section{Abstract}

Background: Tumor necrosis factor- $a$ (TNF-a) is a immunostimulatory cytokine which is consistently high in the breast tumor microenvironment (TME) however its differential role in mitochondrial functions and cell survival in ER/PR +ve and ER/PR-ve breast cancer cells is not well understood.

Methods: In the current study, we investigated TNF-a modulated mitochondrial proteome using highresolution mass spectrometry and identified the differentially expressed proteins of two different breast cancer cell lines: ER/PR positive cell line, luminal: MCF-7 and ER/PR negative cell line, basal-like: MDAMB-231and explored their implication in tumorigenic potential of breast cancer cells. We compared the mitochondrial complex activity, ATP and ROS levels between MCF-7 and MDA-MB-231 in presence of TNF-a. We used Tumor Immune Estimation Resource (TIMER) database to analyze the correlation between TNF- $a$ and mitochondrial proteins in basal and luminal breast cancer patients. KM plotter analysis was used to understand the relation between mitochondrial protein expression and survival of breast cancer patients.

Results: The proteomics experiment showed TNF-a differentially altered the level of critical proteins of mitochondrial respiratory chain complexes both in MCF-7 and MDA-MB-231, which correlated with differential assembly of mitochondrial ETC complexes and activity. The inhibition of glycolytic pathway in presence of TNF-a showed that glycolysis is indispensable for proliferation and clonogenic abilities of MDA-MB-231 (ER/PR - ve) as compared to MCF-7 (ER/PR +ve). The TIMER database showed highly significant negative correlation of TNF-a with key regulators of OXPHOS complexes in basal breast carcinoma as compared to lobular. KM plotter analysis showed improved relapse-free survival with increased expression of identified protein and survival of the breast cancer patients.

Conclusion: Collectively, the results here strongly suggest that TNF-a differentially regulates metabolic adaptation in ER/PR + ve(MCF-7) and ER/PR - ve (MDA-MB-231) cells by modulating the mitochondrial supercomplex assembly and activity hence may be critical factor for determining the tumor progression and survival of the breast cancer patients.

\section{Introduction}

Breast cancer is still leading cause of death in woman worldwide (Coughlin and Ekwueme, 2009), hence requires further understanding of metabolic adaptations of different types of breast cancer for idnetification of newer and alternative drug targets. Broadly, breast cancer has been categorized as hormone responsive ER/PR + ve representing early tumor benign condition whereas ER/PR -ve as aggressive and metastasis at late stage. Solid tumor microenvironment (TME) is complex and constitutes many different cells types including the recruitment of circulating monocytes and its differentiation to tumor associated macrophage (TAM) (Vitale et al., 2019). The interaction of the TAMs and breast cancer cells lead to inflammatory milieu which reprogram the genetic expression landscape in 
tumor cells leading to immune evasion and tumor progression. The mechanisms regulating this process are emerging however not well understood.

Inflammation in TME enhances tumor growth and metastasis in pancreatic, lung, gastric and many other cancers (Padoan et al., 2019; Pierce et al., 2009; Pullamsetti et al., 2017; Qu et al., 2018) including breast cancer. Inflammation affects all phases of malignancy, including proliferation at early stage, angiogenesis, progression, and tumor metastasis(Bachelot et al., 2003; Cai et al., 2017). The increased levels of several proinflammatory cytokines like TNF- $\alpha$, IL-8, IL-10, growth factors like TGF- $\beta$ have been observed in tumor microenvironment(Ma et al., 2017; Mocellin et al., 2005; Yu et al., 2013).Despite such close association of inflammation and tumorigenesis, the mechanisms underlying the cytokine mediated metabolic adaption and regulating clonogenic potential in breast cancer cells is not well understood.

TNF- $a$ is a pleiotropic cytokine and act as pro- or anti-tumorigenic depending upon the stage and type of the cancer. TNF-a level is high in tumors of different origin including breast cancer. Moreover, studies in last decade had shown that mitochondria is emerging as a platform for assembly of the complexes regulating the NF-kB and IFN pathways, hence innate immunity during viral infections. Previously, we have reported that adaptor proteins like STING and NLRX1 localize on mitochondria and its contact site, which beyond their role in innate immunity, can act as tumor suppressor and modulate mitochondrial functions in presence of TNF-a(Bhatelia et al., 2017; Singh et al., 2019).These evidences clearly suggest that mitochondria had been critically placed such that it integrates inflammation and metabolism however its role in presence of altered cytokine levels in TME, regulating tumor growth needs to be further investigated. In the current study we systematically investigated TNF-a modulated mitochondrial proteome by employing quantitative mass spectrometry. We observed that TNF- $a$ can differentially modulate the subunits of mitochondria oxidative phosphorylation (OXPHOS) complexes and mitochondrial functions to regulate the clonogenic abilities of the cells and affects the migration ability.

\section{Materials And Methods}

\section{Cell Lines used and the reagents:}

MCF-7 and MDA-MB-231 cells were cultured in Dulbecco's Modified Eagle's Medium (DMEM, Life Technologies, Carlsbad, CA, USA) Media were supplemented with $10 \% \mathrm{v} / \mathrm{v}$ heat inactivated fetal bovine serum (Life Technologies) 1\% penicillin, streptomycin and neomycin (PSN) antibiotic mixture (Life Technologies). Human TNF-a (premium grade) was purchased from MiltenylBiotec GmbH, Germany.2deoxy-glucose, NAC (N-Acetyl Cysteine) were purchased from Sigma-Aldrich, USA. CM- $\mathrm{H}_{2}$ DCFDA and MitoSOX ${ }^{\mathrm{TM}}$ Red were purchased from Molecular Probes Inc., USA.

\section{Mitochondria Isolation And Quality Control:}

Cells were seeded at $3 \times 10^{6}$ densityand after overnight incubation cells were treated as indicated. The cells were collected and passed through 24GX1" syringe 50-60 times using Sucrose-Tris mitochondria isolation buffer $(0.25 \mathrm{M}$ Sucrose, $10 \mathrm{mM}$ Tris $\mathrm{HCl}$ and $1 \mathrm{X}$ protease inhibitor). After centrifugation at $600 \mathrm{Xg}$ 
for $10 \mathrm{~min}$, the supernatant was collected again and centrifuged at $8000 \mathrm{~g}$, further mitochondrial pellet was collected and purity was checked by western blotting using antibodies against Actin, Tom20, SDHA and UQCRC2.

\section{Sample Preparation And Digestion}

Isolated mitochondrial fractions were lysed with in RIPA lysis buffer (Thermo Scientific, Rockford, IL, USA) with protease inhibitor (Roche Diagnostics, Mannheim, Germany) and phosphatase inhibitor cocktail(Roche Diagnostics), followed by a brief sonication on ice. The cells were sonicated and centrifuged for $15 \mathrm{~min}$ at $24,000 \mathrm{~g}$ at $4{ }^{\circ} \mathrm{C}$, and the supernatant was transferred to a new tube. Protein concentration was determined using BCA assay kit (Thermo Scientific). Protein samples were fractionated on 4-12\% Bis-Tris Gels (Invitrogen, Carlsbad, CA, USA) and stained with Coomassie Brilliant Blue (SigmaAldrich, St. Louis, MO, USA). Each gel lane was cut into ten pieces and subjected to in-gel tryptic digestion following the general protocol(Rosenfeld et al., 1992). Briefly, protein bands were excised, distained, washed, and further reduced with $20 \mathrm{mM}$ DTT and alkylated with $55 \mathrm{mM}$ iodoacetamide. After dehydration, the proteins were digested with $13 \mathrm{ng} / \mathrm{ml}$ sequencing-grade modified porcine trypsin (Promega, Madison, $\mathrm{WI}, \mathrm{USA}$ ) in $50 \mathrm{mM}$ ammonium bicarbonate overnight at $37^{\circ} \mathrm{C}$. Peptides were extracted from the gel slices in $50 \%(\mathrm{v} / \mathrm{v}) \mathrm{ACN}$ and $5 \%(\mathrm{v} / \mathrm{v})$ formic acid, and dried under vacuum.

\section{Mass Spectrometry Analysis}

Peptides were resuspended in $25 \mu \mathrm{L}$ Solvent $\mathrm{A}(0.1 \%$ formic acid in water, $\mathrm{pH} 2.0)$ and $5 \mu \mathrm{L}$ sample was loaded onto an analytic column (PepMap, $75 \mu \mathrm{m} \mathrm{ID} 50 \mathrm{~cm} 3 \mu \mathrm{m}$, ES803, Thermo Fisher Scientific, San Jose, CA, USA) interfaced with a nano-ultra-HPLC system (EasynLC, Thermo Fisher Scientific)and separated with a linear gradient of $5-32 \%$ Solvent B ( $0.1 \%$ formic acid in $A C N)$, time (B\%) $0 \sim 12$ min ( $5 \%$ solvent B), 97 (40\%), 105 (70\%), 117 (70\%), 120 (2\%), for $120 \mathrm{~min}$ at a flow rate $300 \mathrm{~nL} / \mathrm{min}$.MS spectra were recorded on a Q-Exactive Orbitrap mass spectrometer (Thermo Fisher Scientific). The standard mass spectrometric condition of the spray voltage was set to $2.2 \mathrm{kV}$ and the temperature of the heated capillary was set to $250{ }^{\circ} \mathrm{C}$. The full MS scans were acquired in the mass analyzer at $400-1400 \mathrm{~m} / \mathrm{z}$ with a resolution of 70,000 and the MS/MS scans were obtained with a resolution of 17,500 by normalized collision energy of $27 \mathrm{eV}$ for high-energy collisional dissociation fragmentation. The automatic gain control target was $1 \times 10^{5}$, maximum injection time was $120 \mathrm{~ms}$, and the isolation window was set to $2.0 \mathrm{~m} / \mathrm{z}$. The Q-Exactive was operated in data-dependent mode with one survey MS scan followed by ten MS/MS scans, and the duration time of dynamic exclusion was $20 \mathrm{~s}$.

\section{Database Search}

Collected MS/MS data were searched against the decoy UniProt human database (version 3.83, 186578 entries) by Proteome Discoverer 2.2 (PD 2.2, Thermo Scientific) software. Precursor and fragment ion tolerance were set to $10 \mathrm{ppm}$ and $0.5 \mathrm{Da}$, respectively. Trypsin was chosen as the enzyme with a maximum allowance of up to two missed cleavages. Carbamidomethyl(+57.02) of cysteine was considered as the fixed modification, while the variable modification was set for methionine oxidation(+ 
15.99). The result filtration parameters of PD 2.2 were set as follows: peptide and protein identifications were accepted if they could be established at greater than $95 \%$ and $99 \%$ probability, respectively, as specified by the Peptide and Protein Prophet algorithm and if the protein identification contained at least two identified peptides with an false discovery rate $\leq 0.1 \%$.

\section{Relative Protein Quantification And Bioinformatics Analysis}

Relative protein quantitation was accomplished using spectral counting. The MS/MS data were normalized to compare the abundances of proteins between samples using PD 2.2 software. The normalized spectral counts from triplicate analyses of the MCF-7 and MDA-MB-231 cells treated or untreated with TNF-a were compared using the R program (www.R-project.org; version 3.4.3)(Team, 2018)with power law global error model (PLGEM; version 1.50.0) software used to determine signal-tonoise ratio and P-value(Keller, 2002; Pavelka et al., 2008).We filtered statistically significant differentially expressed proteins (DEPs) using 0.01 as a p-value threshold. Then we refined spectral count readouts for the proteins within the range of $0.01 \leq p$-value $\leq 0.05$ using Moment Adjusted Imputation (MAl) equation(Thomas et al., 2011)to identify DEPs with statistical significance with more sensitivity. After the MAl refinements, we have determined p-value with PLGEM and filtered statistically significant DEPs using 0.01 as a p-value threshold. The subcellular localization and functional annotation of the identified proteins were classified using Ingenuity Pathway Analysis (IPA, QIAGEN Inc., Valencia, CA,US) and Protein Analysis through Evolutionary Relationships Classification System ((PANTHER, version 7.2) (Thomas et al., 2003).

\section{BN-PAGE}

MCF7 and MDA-MB231 cells were seeded at density $3 \times 10^{6} / 100 \mathrm{~mm}$ dish. After overnight incubation cells were treated as required. Mitochondria from MCF-7 and MDA-MB231 cells were isolated in TrisSucrose buffer as described above and $50 \mu \mathrm{g}$ pellets were solubilized as per manufacturer's protocol (Thermo Fisher Scientific) and BN-PAGE was performed on Native PAGE Novex3-12\% Bis-Tris Protein Gels (ThermoFisher Scientific). In-gel enzyme activity of different OXPHOS complexes were analyzed on gradient Bis-Tris gel.

For complex I- $1 \mathrm{mg} \mathrm{NADH}$ and $25 \mathrm{mg}$ NTB was used in $2 \mathrm{mM}$ Tris- $\mathrm{HCl}(\mathrm{pH}-7.4)$ and for complex IV- $5 \mathrm{mg}$ DAB and $10 \mathrm{mg}$ cytochrome $\mathrm{C}$ in $50 \mathrm{mM}$ potassium phosphate buffer $(\mathrm{pH}-7.4)$ was used for in gel activity. For complex III- $10 \mathrm{mg}$ 3,3' diaminobenzidine tetrachloride (DAB) and $25 \mathrm{mg}$ Cytochrome $\mathrm{C}$ in $25 \mathrm{ml}$ of $50 \mathrm{mM}$ sodium phosphate buffer ( $\mathrm{pH} 7.2$ ) was used for in gel activity.

\section{Spectrophotometric analysis of mitochondrial Complex I and Complex II assays-}

MCF-7 and MDA-MB231 cells were seeded at the density of $5 \times 10^{5}$ cells/well in the 6-well plate. After overnight incubation, the cells were treated as indicated, harvested, and washed with cold DPBS. The cells were subjected to $2-3$ freeze-thaw cycles in a freeze-thaw complete solution ( $0.25 \mathrm{M}$ sucrose, $20 \mathrm{mM}$ Tris- $\mathrm{HCl}$ (pH 7.4), $40 \mathrm{mM} \mathrm{KCl,} 2 \mathrm{mM}$ EDTA supplemented with $1 \mathrm{mg} / \mathrm{ml}$ fatty acid-free BSA, $0.01 \%$ 
Digitonin and $10 \%$ Percoll). The cells were washed again with the freeze-thaw solution devoid of digitonin and resuspended in Complex I assay buffer ( $35 \mathrm{mM}$ potassium phosphate $(\mathrm{pH} 7.4), 1 \mathrm{mM}$ EDTA. $2.5 \mathrm{mM} \mathrm{NaN3}, 1 \mathrm{mg} / \mathrm{ml}$ BSA, $2 \mu \mathrm{g} / \mathrm{ml}$ antimycin A, $5 \mathrm{mM} \mathrm{NADH})$. The reaction was started by adding $80 \mu \mathrm{g}$ of cell lysate to $500 \mu \mathrm{l}$ of assay buffer in $1 \mathrm{ml}$ quartz cuvette. Complex I activity was measured for $3 \mathrm{~min}$ by monitoring the decrease in absorbance at $340 \mathrm{~nm}$ after the addition of $2.5 \mathrm{mM}$ acceptor decylubiquinone indicating the oxidation of NADH.

Similarly, for Complex II activity, cells were seeded at density of $1.5 \times 10^{6} / 60 \mathrm{~mm}$ dish. The cells were harvested and washed with cold DPBS. All the subsequent steps were performed at $4{ }^{\circ} \mathrm{C}$. The cells were suspended in $0.5 \mathrm{ml}$ of $20 \mathrm{mM}$ hypotonic potassium phosphate buffer $(\mathrm{pH} 7.5)$ and lysed using a $24 \mathrm{G}$ sterile syringe and subjected to freeze-thaw cycle. The cell lysate $(80 \mu \mathrm{g})$ was added to the $1 \mathrm{ml}$ of Complex II assay buffer (0.1M potassium phosphate ( $\mathrm{pH} 7.5), 50 \mathrm{mg} / \mathrm{ml} \mathrm{BSA}, 100 \mathrm{mM} \mathrm{NaN}{ }_{3}, 200 \mathrm{mM}$ succinate) and incubated in water bath for $15-20$ mins at 37 degree. Complex II activity was measured for $6 \mathrm{~min}$ by monitoring the decrease in absorbance at $600 \mathrm{~nm}$ after the addition of $2.5 \mathrm{mM}$ acceptor decylubiquinone and DCPIP.

\section{ATP Assay}

MCF-7 and MDA-MB231 cells were seeded in density of $5 \times 10^{4}$ in 24 well plate. After overnight incubation desired treatments were given and ATP levels were measured in control and treatment conditions by an ATP dependent luciferase assay using ATP determination kit (Molecular Probes/Life Technologies, ON, Canada)

\section{Assay Of Intracellular And Mitochondrial ROS:}

ROS levels were measured by CM- $\mathrm{H}_{2}$ DCFDA $(10 \mu \mathrm{M})$ and MitoSOX Red $(5 \mu \mathrm{M})$ staining, respectively. Briefly, MCF7 and MDA-MB231 cells were plated at the density of $1.5 \times 105$ cells/well in 24 -well plates. The cells were treated with indicated reagents and stained with indicated reagent and monitored under fluorescence microscope (Olympus IX81 microscope; Olympus, Tokyo, Japan). Minimum of 5 images and 80- 100 cells were used for analysis. ROS levels were also quantified by fluorometry. Briefly, MCF-7 and MDA-MB231 cells were transfected with indicated constructs. The cells were treated with indicated reagents and stained with $\mathrm{CM}-\mathrm{H}_{2}$ DCFDA $(12.5 \mu \mathrm{M})$ in DPBS for intracellular ROS quantification and MitoSOX Red $(2.5 \mu \mathrm{M})$ in DMEM for mitochondrial superoxide quantification. The cells were washed with DPBS and normalized to $1 \times 10^{6} \mathrm{cells} / \mathrm{ml}$. Fluorescence intensity was quantified by fluorometer (Hitachi High-Technologies Corp., Japan) with excitation/emission at 495/520-540 nm and 510/570-600 nm, respectively.

\section{MTT Assay}

MCF7 and MDA-MB231 cells were seeded (5000 cells/well) in 96-well plate. After overnight incubation, the cells were treated as indicated. The cell viability was determined using the standard MTT [3-(4,5dimethylthiazol-2-yl)-2,5-diphenyltetrazoliumbromideassay. The purple formazan crystals were dissolved 
in DMSO, transferred in a 96 well plate $(100 \mu \mathrm{L} /$ well $)$ and the absorbance was recorded on a microplate reader at a wavelength of $570 \mathrm{~nm}$.

\section{Clonogenic Assay}

MCF-7 and MDA-MB-231 cells (2000 cells/well) were seeded in 6 well plate and after overnight incubation, desired treatments were given. Cells were kept for 11-12 days and later cells were fixed using methanol and colonies were stained using $0.2 \%$ crystal violet as described earlier(Singh et al., 2015).

\section{Survival Analysis}

BRCA patients in the The Cancer Genome Atlas (TCGA) database were ranked by the level of NDUFB1, SDHA, COX7B and COX4I1 expression and divided into two groups; top quarter and low quarter in expression level. These groups were analyzed in Kaplan-Meier survival plotto estimate the correlation between gene's expression level and survival of patients using OncoLnc (Anaya, 2016)

\section{Wound Scratch Assay}

Scratch assay was performed in MCF-7 and MDA-MB-231 cells. Cells were seeded at density of $2.5 \times 105$ cells per well in 12 well plate. After overnight incubation cells were treated with desired treatments. $24 \mathrm{hrs}$ post treatment a vertical wound was created using sterile P200 micropipette tip. At zero time point first image of each scratch was taken using Nikon Ti-2 eclipse inverted fluorescent microscope at 10X. After 24 hours of treatment each scratch was examined at same area. Migration rate was measured using imageJ software which measures open area at different time interval. The percentage open area in each condition was plotted.

\section{Statistical analysis}

Data are expressed as mean of + SEM of two or three independent experiments. Unpaired two tailed Students t-test were performed. GraphPad prism was used to perform all statistical analysis.

\section{Results}

Quantitative analysis of TNF-amodulated mitochondrial proteome in ER/PR + ve (MCF-7) and ER/PR -ve (MDA-MB-231) breast cancer cells

To identify TNF-a modulated differentially expressed mitochondrial proteins in MCF-7(ER/PR + ve) and MDA-MB-231 (ER/PR - ve) cells, we performed quantitative proteomic analysis of mitochondrial proteins of both cell lines in the presence and absence of TNF-a. Mitochondrial fractions were prepared from MCF7 and MDA-MB-231cells and the purity was assessed by western blotting using selected mitochondrial marker proteins (Tom20, UQCRC2 and SDHA)including nuclei(PARP), cytosol( $\beta$-actin)(Fig. 1A). The mitochondrial fraction of both MCF-7 and MDA-MB-231 showed high level of mitochondrial proteins of TOM20, UQCRC2 and SDHA whereas PARP, marker of nuclei, was not detected. Triplicate LC-MS/MS data 
of MCF-7 +/- TNF- $a$ and MDA-MB-231 +/- TNF-a were searched against the decoy UniProt human database and identified 1,077 and 1,150 mitochondrial proteins (Peptide probability >95\%; Protein probability > 99\%)for MCF-7 and MDA-MB-231 cells, respectively. The list of identified mitochondrial proteins were further compared with mitochondrial protein databases; MitoCarta(Calvo et al., 2016)and Gene Ontology(Pagliarini et al., 2008). It was observed that $57.5 \%$ proteins were overlapped between MDAMB-231 and MCF-7 cells (Fig. 1C).

The quantitative statistical analysis by integrated PLGEM-STNMAI proteomic of triplicate LC-MS/MS data with the $p$-value threshold 0.01 ,identified 108 (62 up-regulated and 49 down-regulated proteins) and 111 (81 up-regulated and 27 down-regulated proteins) differentially expressed proteins (DEPs) in MCF-7 and MDA-MB-231, respectively (Fig. 1C) in presence of TNF-a.Ingenuity pathway analysis (IPA) indicated that DEPs were involved in Mitochondrial function (20\%), Sirtuin Signaling Pathway (18\%), Oxidative Phosphorylation (12\%), Protein ubiquitination Pathway (12\%) and NRF2-mediated Oxidative Stress (10\%) in MCF-7 cells. Interestingly, MDA-MB-231, ER/PR (-ve) cell line IPA showed that proteins involved in mitochondrial dysfunction, oxidative phosphorylation, sirtuin signaling, and fatty acid $\beta$-oxidation were enriched in presence of TNF- $a$ as compared to MCF-7 cell lines (Fig. 1B).

The functional annotation of the DEPs of MCF-7 andMDA-MB-231 cell lines using IPA and hierarchical clustering analysis (Mev software) (Supplementary Fig. 1A) showed distinct cluster of genes regulating specific pathways were modulated in presence of TNF-a. Cluster 1 showsDEPs between MCF-7 andMDAMB-231cellsin presence of TNF-a which are associated with PPARa/RXRa activation, pyrimidine deoxyribonucleotides de novo biosynthesis and salvage pathways of pyrimidine ribonucleotides. Cluster 2 shows that proteins down-regulated in MCF-7 and up-regulated in MDA-MB-231cellsin presence of TNFawhich are associated with mitochondrial function, sirtuin signaling pathway, oxidative phosphorylation, oxidative ethanol degradation, fatty acid a-oxidation, TCA cycle and glutamate biosynthesis. The results here suggest that the TNF-adifferentially modulates mitochondrial proteome in both ER/PR + ve(MCF7)and ER/PR -ve(MDA-MB-231) cells.

\section{TNF-a differentially regulate the level of critical proteins involved in mitochondrial ETC complex assembly}

The electron transport chain complex activity is important for the metabolic adaptation in cancer cells, hence we focused specifically on the proteins of all respiratory complexes. All the known subunits of electron transport chain (ETC) complexes including complexI, II, III, IV were analyzed both in MCF-7 and MDA-MB-231 in presence of TNF-a. The levels of NDUFS3 (a N module component) and NDUFB1 (the component of ND4 module) was significantly decreased in MCF-7 cells in the presence of TNF-a however, increased in MDA-MB-231(Fig. 2A). In comparison, the levels of NDUFA11, matrix-facing subunit of $\mathrm{Cl}$ increased more than ten-fold in the presence of TNF-ain MDA-MB-231 cells and decreased in MCF-7. This suggests that level of mitochondrial complex I proteins are differentially altered in ER/PR + ve(MCF-7)and -ve(MDA-MB-231) cells in presence of TNF-a.

Complex-II is the smallest mitochondrial complex and unique as it forms a part of the TCA cycle as well as a part of ETC hence directly linking metabolism and ETC, hence we analyzed the alterations of all the 
subunits of complex-II both in MCF-7 and MDA-MB-231 cells in presence of TNF-a. Interestingly, MCF-7 showed increased expression of SDHD subunit whereas other subunit like SDHA and assembly factor SDHA11 decreased in mitochondria in presence of TNF-a (Fig. 2B). MDA-MB-231 cells treated with TNF-a showed no change in SDHD whereas SDHA and SDHB showed increased level in mitochondria. The level of SDHA11 was significantly high in mitochondria of TNF-a treated MDA-MB-231 cells as compared to MCF-7.

Mitochondrial complex-III is important complex as it accepts electron both from complex-I and complex-II through ubiquinone. The alteration of complex-III may lead to oxidative stress and accumulation of oncometabolites leading to increased cell proliferation(Weinberg et al., 2019). We further analyzed the level of Complex-III subunits in mitochondria of both MCF-7 and MDA-MB-231 cells in presence of TNF-a. Levels of most complex-III subunits remained same both in MCF-7 and MDA-MB-231 in presence of TNFa. Interestingly, LYRM7, a protein having the LYR (Leucine, Tyrosine, Arginine) consensus sequence binds to HSC20 and facilitate incorporation of Fe-S cluster into UQCRFS1 in complex-III(Maio et al., 2017; Maio et al., 2014)during assembly of the respiratory chain showed altered levels in both cell lines. The level of LYRM7significantlyincreasedinMCF-7 in presence of TNF-aas compared to MDA-MB-231 (Fig. 2C).To confirm the proteomics observation, LYRM7 levels were also analyzed by western blotting. LYRM7 protein levels also increased in mitochondrial fraction of TNF-a treated MCF-7 cells whereas decreased in MDAMB-231 cells(Fig. 2E). UQCRC2, a complex III protein also showed decreased levels in TNF-atreated MDAMB-231 mitochondrial fraction and correlated with proteomics data (Fig. 2E).Similarly, BCS1L, a 419amino-acid chaperone protein, is a member of the family called AAA, an acronym for ATPases associated with various cellular activities. BCS1L is localized in the inner membrane of the mitochondria and presumed to facilitate insertion of Rieske Fe/S protein into precursors to complex III(Cruciat et al., 1999). BCS1L increased in mitochondria of MDA-MB-231 cells in presence of TNF-a treated whereas remained unchanged in MCF-7 cells.

TNF-a induced alteration of complex-IV subunit levels were also analyzed in mitochondrial fraction of both MCF-7 and MDA-MB-231. There was no major change observed in the levels of different cytochrome-c oxidase complex subunits. Interestingly the assembly factors required for the assembly of COX complex were differentially regulated in presence of TNF-a in the breast cancer cells. In complex-IV, COX14 the assembly factor plays important role in translation of the COX1, main constituent of complexIV(Mick et al., 2010).The level significantly decreased in the mitochondria in MDA-MB-231compared to MCF-7 in the presence of TNF-a (Fig. 2D). Similarly, another assembly factor, COX16 was down regulated in MCF-7 cells compared to MDA-MB-231.

Interestingly, these evidences suggest that assembly and modulation of specific mitochondrial ETC complexes are differentially altered in presence of TNF-a.

TNF-a differentially regulates mitochondrial supercomplex organization and activity in ER/PR + ve (MCF7) and ER/PR -ve (MDA-MB-231 cells) breast cancer cells 
To further analyze the implication of TNF- $a$ altered proteins of supercomplexes, we analyzed the assembly and activity of OXPHOS complexes of MCF-7 and MDA-MB-231 cells in presence/absence of TNF-a. We observed that TNF-a decreased the assembly and activity of supercomplex (SC) containing $\mathrm{Cl}$ and CIV in both the cell line, however decrease was significantly higher in MDA-MB-231 cells in the presence of TNF-a (Fig. 3A). A significant decrease in individual Complex III activity was observed in MDA-MB-231 in presence of TNF-a compared to MCF-7 (Fig. 3B).

To further strengthen the observed effect we performed spectrophotometric analysis of individual OXPHOS complexes ( $\mathrm{Cl}$ and $\mathrm{CII}$ ) activity inMCF-7 and MDA-MB-231 cells in the presence of TNF-a.We also used glucose analog, 2-deoxyglucose (2DG), which inhibits glycolysis, and decreases the growth of tumor cells, which are primarily dependent on the glycolytic pathway (Lucantoni et al., 2018). We analyzed $\mathrm{Cl}$ and $\mathrm{Cll}$ activity both in MCF-7 and MDA-MB-231 cells in the presence of TNF-a either alone or in combination with 2-DG.Complex-I activity significantly decreased in presence of TNF-ain MDA-MB-231 as compared to MCF-7 cells. The inhibition of glycolysis with 2DG increased the Cl activity in MCF-7 in presence of TNF-a. Interestingly, complex-I activity decreased in MDA-MB-231 by inhibiting glycolysis by $2 D G$ and remained unchanged in presence of $2 D G$ with TNF- $a$ (Fig. 3B). This data suggests that glycolysis is essential for the MDA-MB-231 cells to maintain the $\mathrm{Cl}$ activity compared to MCF-7 in presence of TNF-a.

Complex-II activity showed no significant change in the presence of TNF-abut increased significantly in presence of 2DG in MDA-MB-231 (Fig. 3C). Complex-II activity remained same in MCF-7 in presence of TNF-a however decreased in MDA-MB-231 cells. These results suggest that TNF-a modulates the assembly of some critical component of CI,CIII and CIV in MDA-MB-231 cells (ER/PR - ve) and complex-I and complex-III activity decreases in presence of TNF-ain comparison to MCF-7.

\section{TNF-a differentially regulates ATP levels and ROS generation in MDA-MB-231 cells}

To investigate the effect of TNF-a regulated OXPHOS complexes assembly/activity on the mitochondrial bioenergetic status of both the cells, we analyzed the ATP levels and ROS generation in the presence/absence of TNF-a. TNF-asignificantly decreased levels of both mitochondrial and total cellular ATP of MDA-MB-231 cells but not in MCF-7 cells. MCF-7 cells cultured in presence of 2-DG in the presence/absence of TNF-a showed significant decrease in total ATP levels however mitochondrial ATP level increased suggesting enhanced OXPHOS activity in MCF-7 cells in presence of TNF-a on inhibiting the glycolysis (Fig. 4A and 4B). In contrast, MDA-MB-231 cells displayed increased sensitivity to decrease in both mitochondrial and total cellular ATP levels in the presence of TNF-a with or without 2-DG (Fig. 4A and $4 B$ ). This result suggested that MDA-MB-231 cells are strongly dependent on glycolysis mediated mitochondrial pathway of ATP generation which is altered in presence of TNF-a.

Similarly, both intracellular and mitochondrial ROS levels significantly increased in both cell lines however MDA-MB-231 cells displayed an enhanced ROS generation in the presence of TNF-a (Fig. 4C) as compared to MCF-7. Altogether, these results strongly suggested that TNF-adifferentially regulate mitochondrial ETC activity in generation of ATP and ROS in MCF-7 and MDA-MB-231 cells. 
TNF-a modulated mitochondrial functions differentially regulate migration and clonogenic ability of breast cancer cells

To further investigate tumorigenic potential in ER/PR + ve: MCF-7 and ER/PR-ve: MDA-MB-231 cells we analyzed the clonogenic ability in presence/absence of TNF-a. Interestingly, TNF-a inhibits the clonogenic ability of MCF-7 cells whereas enhanced clonogenicity of MDA-MB-231 cells (Fig. 5B). The addition of glycolytic inhibitor:2DG in presence of TNF-a further reduced clonogenic ability of the MDA-MB-231 cells suggesting the glycolysis is essential for MDA-MB-231 cells. The rescue of clonogenicity was observed in presence of NAC (N-Acetyl cysteine), a ROS scavenger in MDA-MB-231 cells whereas it was not observed in the MCF-7 cells suggesting that it is not ROS but electron acceptor ability to maintain the ratio of NAD/NADH ratio in the cell to drive the TCA cycle and glycolysis. This is further supported by the clonogenic ability in the presence of pyruvate. The presence of pyruvate can rescue clonogenic ability in presence of TNF-ain MCF-7 (Fig. 5C). Interestingly there was no major change in pyruvate stimulated clonogenic ability of MDA-MB-231 cells in presence of TNF-a.We also checked the migration ability of both cells in presence of TNF- $a$ and observed that TNF- $a$ enhanced the migration ability of MDA-MB-231 cells as compared to MCF-7 (Fig. 5A).

To further confirm we checked for cell viability MDA-MB-231 in presence/absence of TNF-a in combination with Hemin by MTT assay. Hemin is known to degrade BTB and CNC homology1 (BACH1), a haem binding transcription factor which is increased in tumors from patients with TNBC enhance the mitochondrial respiratory activity(Lee et al., 2019). Hence, we treated the cells Hemin in presence and absence of TNF-a. We observed that the cell viability of MDA-MB-231 cells significantly decreased in presence of TNF- $a$ and Hemin, which is known to enhance the mitochondrial proteins and function together. This suggests that enhancing the mitochondrial proteins and functions in MDA-MB-231 cells in presence of TNF-a, which increases the cell viability, can help in reducing the cell survivability (Fig. 5D).

These results suggest that TNF-a modulated mitochondrial functions differentially regulate migration and clonogenic ability of breast cancer cells and hemin can be a potential target in combination with TNF-a to reduce the cell viability of highly metastatic breast cancer cells.

\section{Subunit of mitochondrial complexes negatively correlates with survival of the breast cancer patients}

The TIMER database is a web resource used for systemic analysis and evaluation of clinical impacts of different immune factors in diverse cancer types hence we analyzed the correlation between TNF- $\mathrm{a}$ and the expression level of identified DEPs. The levels of mitochondrial proteins in presence of TNF-a strongly correlates with the gene expression correlation using TIMER database in Basal and Luminal breast cancer patient data. The TIMER data showed that increased expression of TNF- $a$ in basal breast cancer patients is associated with decreased gene expression of $\mathrm{Cl}$ mitochondrial subunits. This negative correlation between TNF-a and Complex-I subunits is significantly higher in basal breast cancer patients (Fig. 6A).We did not observe any correlation in luminal breast cancer patients. CIII subunits like UQCR10, UQCRB and UQCRQ expression was also altered in basal breast cancer patients which showed a 
significant negative correlation with TNF-a expression as compared to luminal breasts cancer patients (Fig. 6B).

We also checked the survivability of breast cancer patients using the Kaplan Meier survival plot analysis. The high expression of subunits of mitochondrial complexes like NDUFB1 $(p=0.052)$, SDHA $(p=0.011)$ and $\operatorname{COX7}(p=0.064)$ showed increased percentage of survival and increased the number survival days. (Fig. 6C)

These evidences strongly suggest that TNF-a differentially regulates the mitochondrial subunits and mitochondrial functions of in ER/PR + ve: MCF-7 and ER/PR-ve: MDA-MB-231 to regulate tumorigenic potential of the tumor cells and survivability of the breast cancer patients.

\section{Discussion}

Mitochondria is important for metabolic adaptations in different conditions including presence of cytokine in tumor microenvironment. The regulation of TNF-a mediated mitochondrial complex assembly and its role in regulation of clonogenic abilities of breast cancer cells had not been systemically investigated. To understand the differential regulation, we here systemically characterized mitochondrial proteome of two different cell types MCF-7: ER/PR + ve, responsive representing early tumor conditions and MDA-MB-231 cells: ER/PR - ve representing aggressive and metastatic conditions tumor cell types. There is no systemic study monitoring the mitochondrial proteome in different breast cancer cells which determines differential metabolic adaptations in TME. There are some previous reports where TRAIL, member of TNF-a family, modulated total cellular proteome had been analyzed (Leong et al., 2012) however total cellular proteome truly do not reflect mitochondrial proteins (Chen et al., 2018). Hence it is important to understand the TNF-a modulated mitochondrial proteome to understand the differential mitochondrial role in driving the tumor characteristic and heterogeneity.

The high-resolution proteomics clearly showed that TNF-adifferentially modulates mitochondrial proteome of MDA-MB-231 and MCF-7 cells leading to differential mitochondrial function and OXPHOS capacity. There are other pathways that are differentially regulated in presence of TNF-a like sirtuin pathways and iron homeostasis in MCF-7 and MDA-MB-231 cells, which also regulate mitochondrial functions however this can be topic of further investigation. The study further focused on the assembly of mitochondrial respiratory chain complexes which are differentially regulated in MCF-7 and MDA-MB231 cells. The level of mitochondrial DNA encoded transcripts specifically ND2 and ND3 which forms the part of the core unit of the complex-I, increased in MCF-7 whereas remain unaltered in MDA-MB-231 cells. The levels of NDUFS3 (a N module component) and NDUFB1 (the component of ND4 module) was significantly decreased in MCF-7 cells in the presence of TNF-a however, increased in MDA-MB-231 suggesting that TNF-a can differentially modulate the complex-I activity which is in consonance with in gel and super complex assembly.

Similarly, mitochondrial complex-III, which can accept electron from both complex-I and complex-II through ubiquinone is critical for mitochondrial forms and functions. The study here showed decrease in 
complex-III activity which correlates with observations of proteomics data, as observed above. The level of assembly factor LYRM7 decreased in MDA-MB-231 cells compared to MCF-7 cells. Emerging report suggest that binding of HSC20 (co-chaperone) to the LYR motif of LYRM7 in a pre-assembled UQCRFS1LYRM7 intermediate in the mitochondrial matrix facilitates Fe-S cluster transfer to UQCRFS1, hence assembly of complex-III. This decrease in LYRM7 in mitochondria of MDA-MB-231 cells strongly suggest that incorporation of Fe-S complexes in mitochondrial electron transport chain may be modulated in all the complexes of mitochondria including II II, III hence flux of NADH which determines level of TCA cycle intermediates shifting the equilibrium for the anaplerotic reactions in aggressive breast tumor cells (MDAMB-231). Similarly decrease in complex-I/III activity may also generate higher level of ROS in triple negative aggressive breast cancer cells which may act as mitohormetic response rather than cell death. This is in consonance with recent report where it had been observed that mitohormetic response generated in selected aggressive breast cancer cells from the patient can induce the nuclear gene modulation which may help to survive in the hostile tumor microenvironment. (Kenny et.al. 2019)

This is further supported by the analysis of clonogenic abilities of the cells in the presence of TNF-a. Interestingly we observed that TNF-a inhibited clonogenic ability of MCF-7 cells is rescued in presence of pyruvate suggesting that electron acceptors is limiting factor. Pyruvate level can be differentially regulated in MCF-7/MDA-MB-231 cells, which is known to act as electron acceptor and can determine the cell proliferation. Interestingly, in MDA-MB-231, highly metastatic cells, pyruvate is not limiting factor as TNF-a reprogrammed the activity of OXPHOS for anaplerotic reaction, as we observed pyruvate supplementation showed no major effect on cell proliferation or clonogenic abilities of the cells. This observation further supported as we observed high level of pyruvate in MDA-MB-231 cells as compared to MCF-7 cells (unpublished observation)

Our observation supports the hypothesis that TNF-a in solid tumor can dictate the mitochondrial complexes activity to maintain the proliferation in hostile solid TME. The overall decrease in the mitochondrial proteins and complex activity in MDA-MB-231 is supported by recent study where BTB and CNC homology1 (BACH1), a haem binding transcription factor increased in tumors from patients with TNBC and which decreases glucose utilization in the tricarboxylic acid cycle and negatively regulates transcription of electron transport chain (ETC) genes(Lee et al., 2019). It was observed that enhancing the reliance of breast cancer cells to mitochondrial functions by modulating the transcription factor BACH1 using hemin sensitizes the cancer cells to metformin. In our study the TIMER database showed negative correlation of $\mathrm{Cl}$ and $\mathrm{CIII}$ subunits with TNF-ain Basal breast cancer patients. This very well relates with the decrease observed in complex assembly and activity in MDA-MB-231 in presence of TNF- $a$ in the present study. Further the survivability of the breast cancer patients also correlates with expression of mitochondrial complexes.

In conclusion subcellular proteomics had helped to understand the differential behavior of the ER/PR + ve and ER/PR -ve breast cancer cells in tumor microenvironment where the level of TNF-a is high(Marrugal et al., 2016).The evidences here clearly suggest that TNF-a modulates the aggressive tumor cells by modulating the levels of critical assembly factors and subunits involved in mitochondrial respiratory 
chain super complexes favoring metabolic reprogramming towards anaplerotic reaction in breast cancer cells. This study identified novel assembly factors as possible therapeutic target to prevent the progression of aggressive breast cancer cells hence survival of the breast cancer patients.

\section{Conclusion}

Our study highlights that TNF-a, high in TME differentially regulate the levels of proteins of mitochondrial OXPHOS complexes and activity in hormone responsive ER/PR + ve and ER/PR - ve metastatic breast cancer cells. The TIMER data and KM plot analysis supports that survivability negatively correlates with levels of OXPHOS subunits suggesting role in metabolic adaptions in breast cancer and its implication in therapeutics.

\section{Abbreviations}

TME- Tumor microenvironment, TNF-a- Tumor necrosis factor alpha, ER- Estrogen receptor, PRProgesterone receptor, TAM-Tumor associated macrophages, OXPHOS-Oxidative phosphorylation, ETCElectron transport chain, Tumor Immune Estimation Resource (TIMER), ATP- Adenosine triphosphate, ROS- Reactive oxygen species, NAC- N-acetylcysteine, TNBC-Triple negative breast cancer

\section{Declarations}

\section{Ethics approval and consent to participate}

Not applicable.

\section{Consent for publication:}

Consent to publish this paper from all the participants is obtained.

\section{Funding:}

This work was supported by Department of Science and Technology, Govt. of India, grant number INT/Korea/P-39 to Prof. Rajesh Singh. Global Infrastructure Program through the NRF funded by the Ministry of Science and ICT (NRF-2017K1A3A1A19071651 to ECY) and National Research Foundation of Korea (NRF) Grant funded by the Korean Government (MSIP) (NRF-2016R1A5A1010764 and NRF2015M3A9B6073835 to ECY)

\section{Authors Contribution:}

R.S. and E.C.Y conceptualized and designed the experiments, analyzed proteomics data and wrote the manuscript. A.S., H.L. and K.S. performed the experiments and wrote the manuscript. M.R. helped with data analysis and TIMER data correlation. D.G. helped with mitochondrial experiments. M.M., H.V. and 
F.C. assisted with in vitro experiments. H.R.J. and Y.S. performed the metabolite extraction, H.B.K., A.C. and S.J.Y. performed targeted metabolomics and analyzed the data.

\section{Acknowledgement:}

Authors acknowledge the instrumentation facility at Department of Biochemistry, The M. S. University of Baroda, Vadodara. Kritarth Singh received Senior Research fellowship from University Grants Commission (UGC), Govt. of India. We also acknowledge DST FIST for providing instrumentation facility for the work.

\section{References}

Anaya, J.M. (2016). OncoLnc: linking TCGA survival data to mRNAs, miRNAs, and IncRNAs. Peer J Computer Science.

Bachelot, T., Ray-Coquard, I., Menetrier-Caux, C., Rastkha, M., Duc, A., and Blay, J.Y. (2003). Prognostic value of serum levels of interleukin 6 and of serum and plasma levels of vascular endothelial growth factor in hormone-refractory metastatic breast cancer patients. Br J Cancer 88, 1721-1726.

Bhatelia, K., Singh, K., Prajapati, P., Sripada, L., Roy, M., and Singh, R. (2017). MITA modulated autophagy flux promotes cell death in breast cancer cells. Cell Signal 35, 73-83.

Cai, X., Cao, C., Li, J., Chen, F., Zhang, S., Liu, B., Zhang, W., Zhang, X., and Ye, L. (2017). Inflammatory factor TNF-alpha promotes the growth of breast cancer via the positive feedback loop of TNFR1/NFkappaB (and/or p38)/p-STAT3/HBXIP/TNFR1. Oncotarget 8, 58338-58352.

Calvo, S.E., Clauser, K.R., and Mootha, V.K. (2016). MitoCarta2.0: an updated inventory of mammalian mitochondrial proteins. Nucleic Acids Res 44, D1251-1257.

Chen, A., Chen, Z., Xia, Y., Lu, D., Jia, J., Hu, K., Sun, A., Zou, Y., Qian, J., and Ge, J. (2018). Proteomics Analysis of Myocardial Tissues in a Mouse Model of Coronary Microembolization. Front Physiol 9, 1318.

Coughlin, S.S., and Ekwueme, D.U. (2009). Breast cancer as a global health concern. Cancer Epidemiol 33, 315-318.

Cruciat, C.M., Hell, K., Folsch, H., Neupert, W., and Stuart, R.A. (1999). Bcs1p, an AAA-family member, is a chaperone for the assembly of the cytochrome bc(1) complex. EMBO J 18, 5226-5233.

Fendt, S.M., Bell, E.L., Keibler, M.A., Olenchock, B.A., Mayers, J.R., Wasylenko, T.M., Vokes, N.I., Guarente, L., Vander Heiden, M.G., and Stephanopoulos, G. (2013). Reductive glutamine metabolism is a function of the alpha-ketoglutarate to citrate ratio in cells. Nat Commun 4, 2236.

Keller, A., Nesvizhskii, A. I., Kolker, E., Aebersold, R (2002). Empirical statistical model to estimate the accuracy of peptide identifications made by MS/MS and database search. Anal Chem. 
Lawrence, T. (2009). The nuclear factor NF-kappaB pathway in inflammation. Cold Spring Harb Perspect Biol 1, a001651.

Lee, J., Yesilkanal, A.E., Wynne, J.P., Frankenberger, C., Liu, J., Yan, J., Elbaz, M., Rabe, D.C., Rustandy, F.D., Tiwari, P., et al. (2019). Effective breast cancer combination therapy targeting BACH1 and mitochondrial metabolism. Nature 568, 254-258.

Leong, S., Nunez, A.C., Lin, M.Z., Crossett, B., Christopherson, R.I., and Baxter, R.C. (2012). iTRAQ-based proteomic profiling of breast cancer cell response to doxorubicin and TRAIL. J Proteome Res 11, 35613572 .

Lucantoni, F., Dussmann, H., and Prehn, J.H.M. (2018). Metabolic Targeting of Breast Cancer Cells With the 2-Deoxy-D-Glucose and the Mitochondrial Bioenergetics Inhibitor MDIVI-1. Front Cell Dev Biol 6, 113.

Ma, Y., Ren, Y., Dai, Z.J., Wu, C.J., Ji, Y.H., and Xu, J. (2017). IL-6, IL-8 and TNF-alpha levels correlate with disease stage in breast cancer patients. Adv Clin Exp Med 26, 421-426.

MacLean, B., Tomazela, D.M., Shulman, N., Chambers, M., Finney, G.L., Frewen, B., Kern, R., Tabb, D.L., Liebler, D.C., and MacCoss, M.J. (2010). Skyline: an open source document editor for creating and analyzing targeted proteomics experiments. Bioinformatics 26, 966-968.

Maio, N., Kim, K.S., Singh, A., and Rouault, T.A. (2017). A Single Adaptable Cochaperone-Scaffold Complex Delivers Nascent Iron-Sulfur Clusters to Mammalian Respiratory Chain Complexes I-III. Cell Metab 25, 945-953 e946.

Maio, N., Singh, A., Uhrigshardt, H., Saxena, N., Tong, W.H., and Rouault, T.A. (2014). Cochaperone binding to LYR motifs confers specificity of iron sulfur cluster delivery. Cell Metab 19, 445-457.

Maolake, A., Izumi, K., Natsagdorj, A., Iwamoto, H., Kadomoto, S., Makino, T., Naito, R., Shigehara, K., Kadono, Y., Hiratsuka, K., et al. (2018). Tumor necrosis factor-alpha induces prostate cancer cell migration in lymphatic metastasis through CCR7 upregulation. Cancer Sci 109, 1524-1531.

Marrugal, A., Ojeda, L., Paz-Ares, L., Molina-Pinelo, S., and Ferrer, I. (2016). Proteomic-Based Approaches for the Study of Cytokines in Lung Cancer. Dis Markers 2016, 2138627.

Mick, D.U., Vukotic, M., Piechura, H., Meyer, H.E., Warscheid, B., Deckers, M., and Rehling, P. (2010). Coa3 and Cox 14 are essential for negative feedback regulation of $\mathrm{COX} 1$ translation in mitochondria. $\mathrm{J}$ Cell Biol $191,141-154$.

Mocellin, S., Rossi, C.R., Pilati, P., and Nitti, D. (2005). Tumor necrosis factor, cancer and anticancer therapy. Cytokine Growth Factor Rev 16, 35-53.

Padoan, A., Plebani, M., and Basso, D. (2019). Inflammation and Pancreatic Cancer: Focus on Metabolism, Cytokines, and Immunity. Int J Mol Sci 20. 
Pagliarini, D.J., Calvo, S.E., Chang, B., Sheth, S.A., Vafai, S.B., Ong, S.E., Walford, G.A., Sugiana, C., Boneh, A., Chen, W.K., et al. (2008). A mitochondrial protein compendium elucidates complex I disease biology. Cell 134, 112-123.

Pavelka, N., Fournier, M.L., Swanson, S.K., Pelizzola, M., Ricciardi-Castagnoli, P., Florens, L., and Washburn, M.P. (2008). Statistical similarities between transcriptomics and quantitative shotgun proteomics data. Mol Cell Proteomics 7, 631-644.

Pierce, B.L., Ballard-Barbash, R., Bernstein, L., Baumgartner, R.N., Neuhouser, M.L., Wener, M.H., Baumgartner, K.B., Gilliland, F.D., Sorensen, B.E., McTiernan, A., et al. (2009). Elevated biomarkers of inflammation are associated with reduced survival among breast cancer patients. J Clin Oncol 27, 34373444.

Pullamsetti, S.S., Kojonazarov, B., Storn, S., Gall, H., Salazar, Y., Wolf, J., Weigert, A., El-Nikhely, N., Ghofrani, H.A., Krombach, G.A., et al. (2017). Lung cancer-associated pulmonary hypertension: Role of microenvironmental inflammation based on tumor cell-immune cell cross-talk. Sci Transl Med 9.

Putignani, L., Raffa, S., Pescosolido, R., Rizza, T., Del Chierico, F., Leone, L., Aimati, L., Signore, F., Carrozzo, R., Callea, F., et al. (2012). Preliminary evidences on mitochondrial injury and impaired oxidative metabolism in breast cancer. Mitochondrion 12, 363-369.

Qu, X., Tang, Y., and Hua, S. (2018). Immunological Approaches Towards Cancer and Inflammation: A Cross Talk. Front Immunol 9, 563.

Rosenfeld, J., Capdevielle, J., Guillemot, J.C., and Ferrara, P. (1992). In-gel digestion of proteins for internal sequence analysis after one- or two-dimensional gel electrophoresis. Anal Biochem 203, 173-179.

Selak, M.A., Armour, S.M., MacKenzie, E.D., Boulahbel, H., Watson, D.G., Mansfield, K.D., Pan, Y., Simon, M.C., Thompson, C.B., and Gottlieb, E. (2005). Succinate links TCA cycle dysfunction to oncogenesis by inhibiting HIF-alpha prolyl hydroxylase. Cancer Cell 7, 77-85.

Singh, K., Poteryakhina, A., Zheltukhin, A., Bhatelia, K., Prajapati, P., Sripada, L., Tomar, D., Singh, R., Singh, A.K., and Chumakov, P.M. (2015). NLRX1 acts as tumor suppressor by regulating TNF-alpha induced apoptosis and metabolism in cancer cells. Biochim Biophys Acta 1853, 1073-1086.

Singh, K., Roy, M., Prajapati, P., Lipatova, A., Sripada, L., Gohel, D., Singh, A., Mane, M., Godbole, M.M., Chumakov, P.M., et al. (2019). NLRX1 regulates TNF-alpha-induced mitochondria-lysosomal crosstalk to maintain the invasive and metastatic potential of breast cancer cells. Biochim Biophys Acta Mol Basis Dis $1865,1460-1476$.

Sullivan, L.B., Gui, D.Y., Hosios, A.M., Bush, L.N., Freinkman, E., and Vander Heiden, M.G. (2015). Supporting Aspartate Biosynthesis Is an Essential Function of Respiration in Proliferating Cells. Cell 162, 552-563. 
Team, R.C. (2018). R: A language and environment for statistical computing. R Foundation for Statistical Computing. In Vienna, Austria.

Thomas, L., Stefanski, L., and Davidian, M. (2011). A moment-adjusted imputation method for measurement error models. Biometrics 67, 1461-1470.

Thomas, P.D., Campbell, M.J., Kejariwal, A., Mi, H., Karlak, B., Daverman, R., Diemer, K., Muruganujan, A., and Narechania, A. (2003). PANTHER: a library of protein families and subfamilies indexed by function. Genome Res 13, 2129-2141.

Tretter, L., Patocs, A., and Chinopoulos, C. (2016). Succinate, an intermediate in metabolism, signal transduction, ROS, hypoxia, and tumorigenesis. Biochim Biophys Acta 1857, 1086-1101.

Vitale, I., Manic, G., Coussens, L.M., Kroemer, G., and Galluzzi, L. (2019). Macrophages and Metabolism in the Tumor Microenvironment. Cell Metab 30, 36-50.

Weinberg, S.E., Singer, B.D., Steinert, E.M., Martinez, C.A., Mehta, M.M., Martinez-Reyes, I., Gao, P., Helmin, K.A., Abdala-Valencia, H., Sena, L.A., et al. (2019). Mitochondrial complex III is essential for suppressive function of regulatory T cells. Nature 565, 495-499.

Yu, M., Zhou, X., Niu, L., Lin, G., Huang, J., Zhou, W., Gan, H., Wang, J., Jiang, X., Yin, B., et al. (2013). Targeting transmembrane TNF-alpha suppresses breast cancer growth. Cancer Res 73, 4061-4074.

Zhou, J., Fandrey, J., Schumann, J., Tiegs, G., and Brune, B. (2003). NO and TNF-alpha released from activated macrophages stabilize HIF-1alpha in resting tubular LLC-PK1 cells. Am J Physiol Cell Physiol 284, C439-446.

\section{Figures}




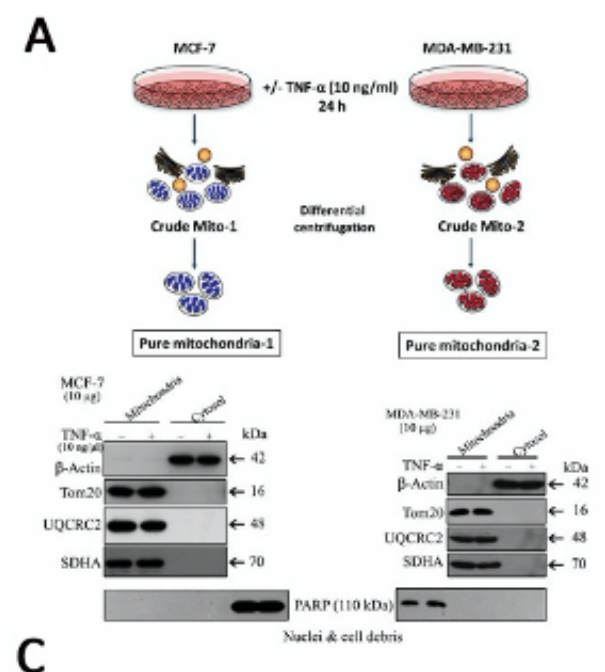

C

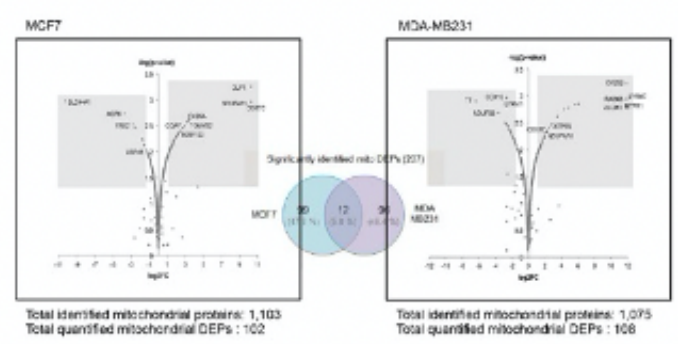

B
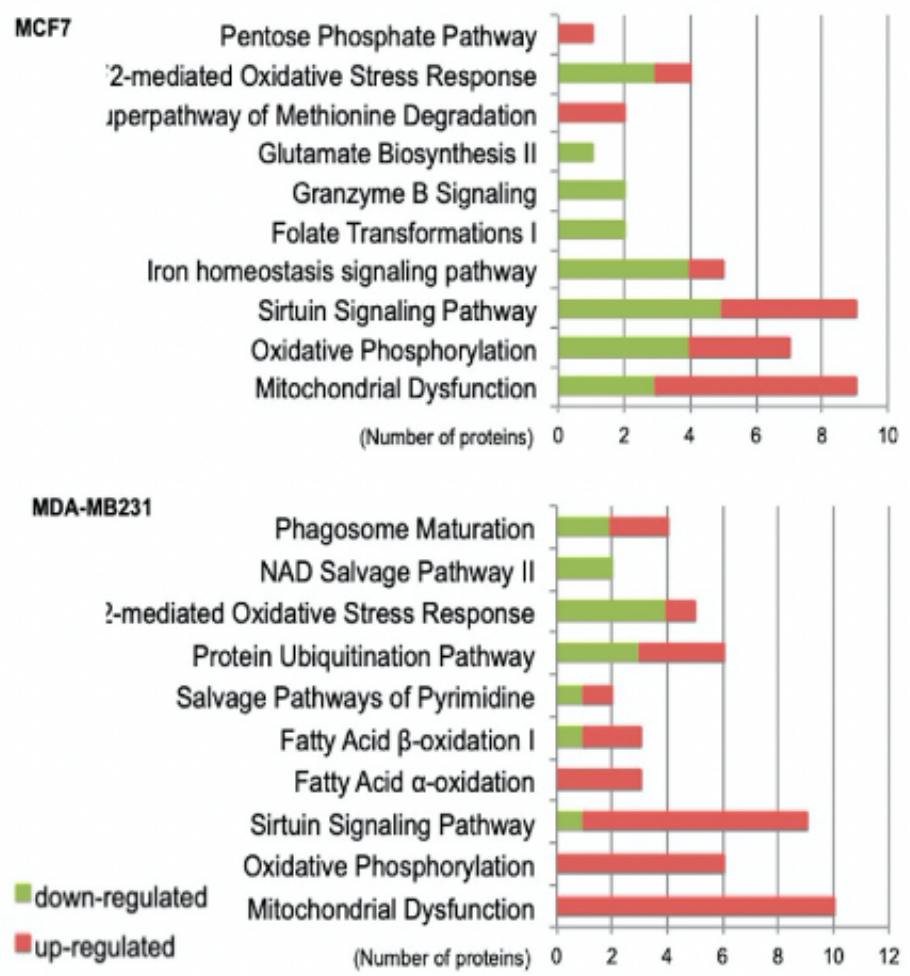

\section{Figure 1}

Quantitative proteomic analysis of TNF-aregulated mitochondrial proteins in breast cancer cells. (A)Immunoblot analysis of isolated mitochondria (B)Molecular functions of DEPs by IPA tool. The x-axis indicates the number of proteins, red bar as up-regulated and green bar as down-regulated proteins. (C)Volcano plots of DEPs displayed in the P-value (- $\log 10)$ versus signal-to-noise ratio (STN). The pvalue and STN were determined by power law global error model (PLGEM) statistical analysis for labelfree quantification 
A
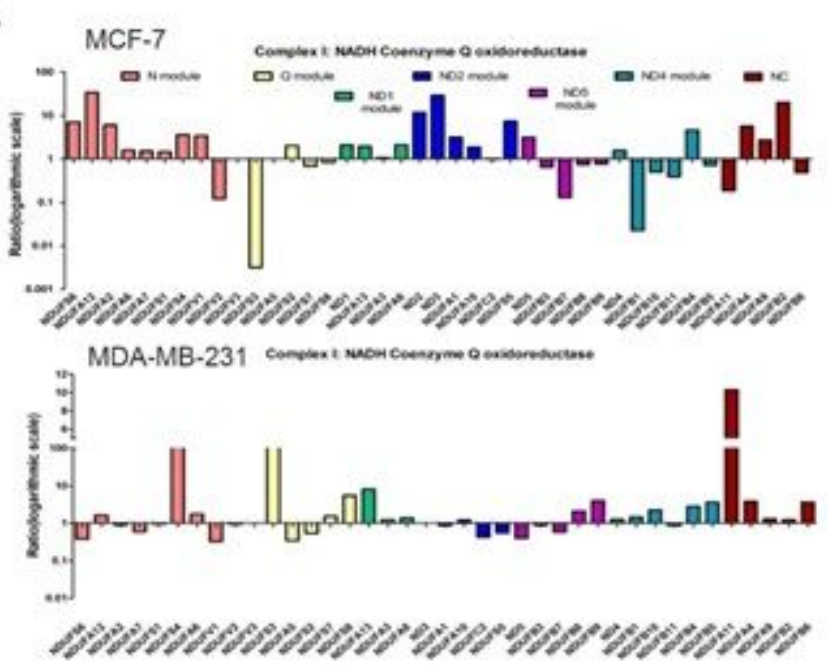

B

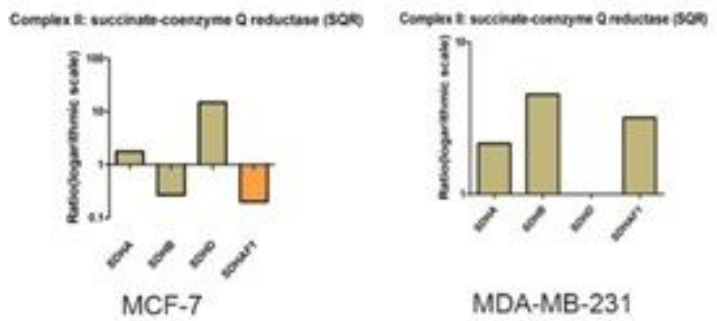

$E$

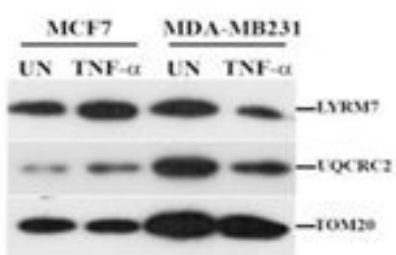

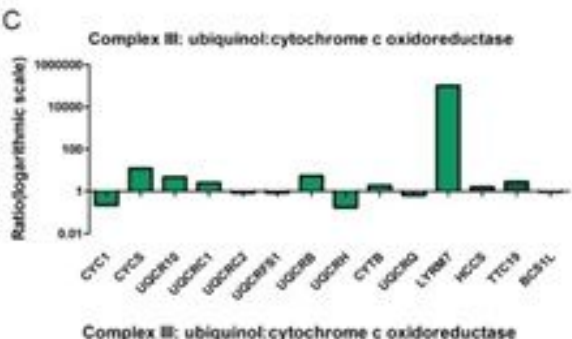

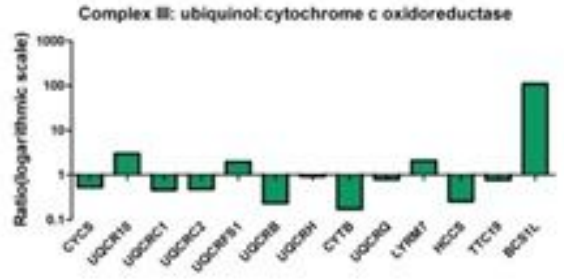

MDA-MB-231

D
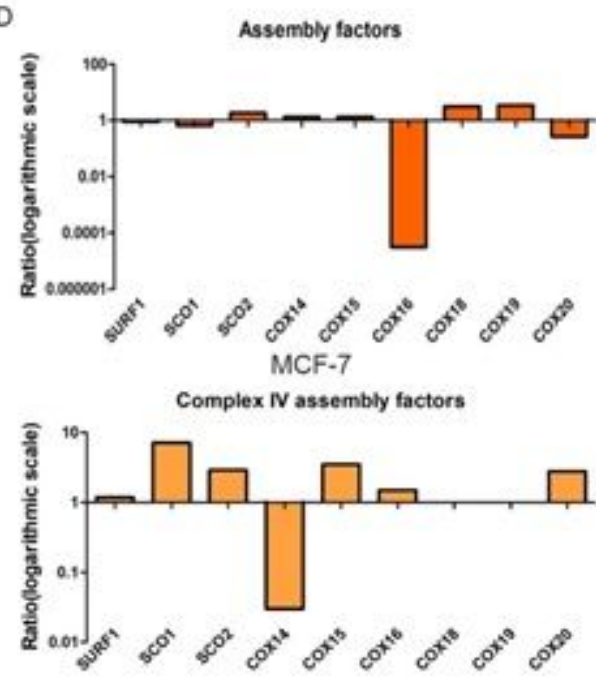

MDA-MB-231

Figure 2

Alteration in protein abundance, as determined by proteomic study corelates with TNF-aregulated mitochondrial function in breast cancer cells. The raw protein abundance count of mitochondrial protein subunits from untreated and TNF-a treated triplicates from both cells were exported and plotted as ratio of log-fold change. The encircled proteins show the log-fold change of unique proteins in both cells. (A) The protein subunits of the $\mathrm{Cl}$ complex are clustered and color-coded into respective modules according to their function. NC represents non-characterized component of $\mathrm{Cl}$ complex. (B),(C)\&(D) The log-fold change of unique proteins for CII, CIII \& CIV in both cell lines respectively (E)western blot analysis of complex III proteins UQCRC2 and LYRM7 in presence MCF-7 and MDA-MB-231 in presence of TNF-a 

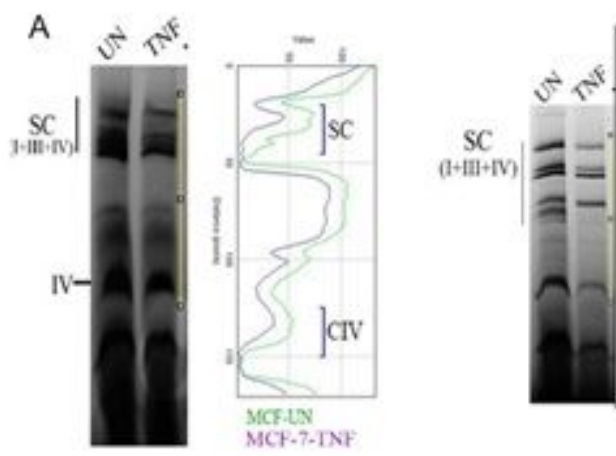

BN-PAGE: IGA-Cl + CIV

C

MCF-7 COMPLEX-1

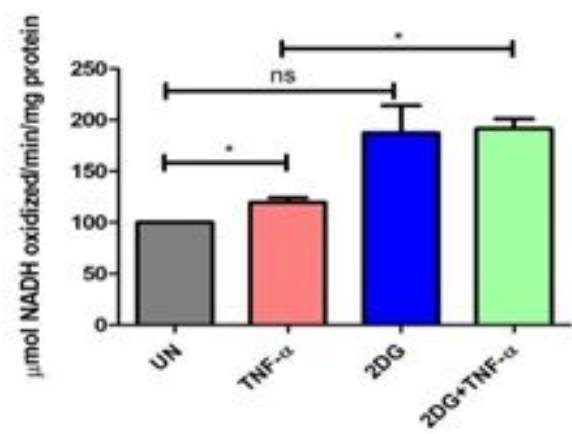

D

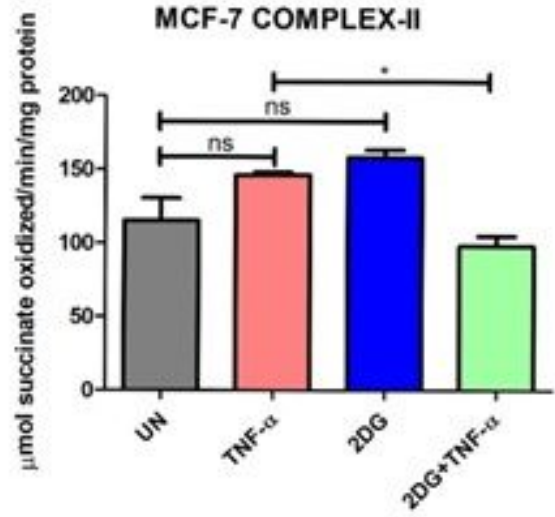

B

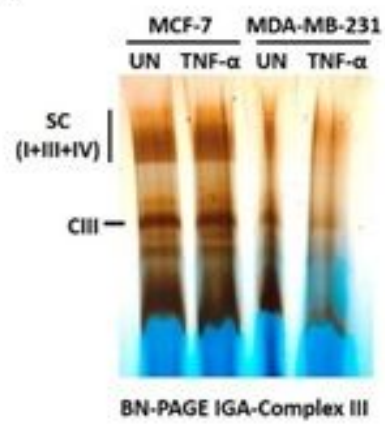

MDA-MB-231 COMPLEX-1

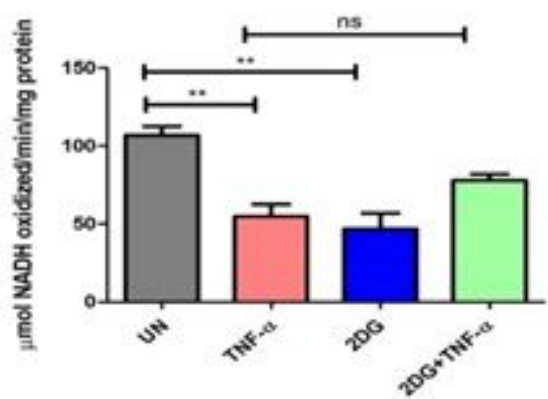

MDA-MB-231 COMPLEX-II

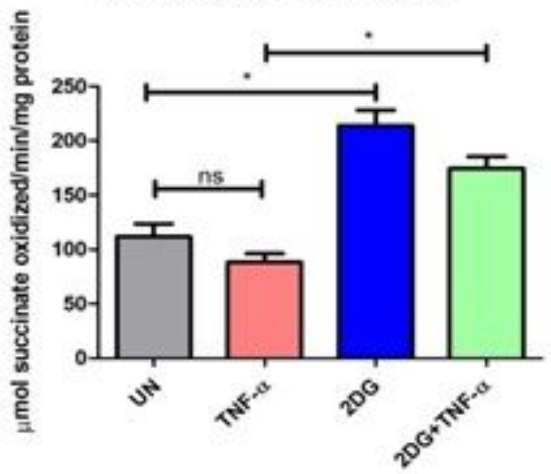

Figure 3

TNF-a alters the OxPhos assembly and activity in breast cancer cells. (A) MCF-7 and MDA-MB-231 cells were treated with TNF-a $(10 \mathrm{ng} / \mu \mathrm{l})$ for $24 \mathrm{~h}$. After treatment, mitochondrial fraction was isolated and further analyzed by BN-PAGE and in-gel enzyme staining for $\mathrm{Cl}$ and $\mathrm{CIV}$ was performed as described in Methodology. (B)Complex III in gel activity was analyzed by BN-PAGE and enzyme staining as described in methodology (C) \& (D) MCF-7 and MDA-MB-231 cells were treated with TNF-a $(10 \mathrm{ng} / \mu \mathrm{l})$ and 2-DG (10 $\mathrm{mM}$ ) either alone or in combination for $24 \mathrm{~h}$ and Complex-I and Complex-II activity was measured spectrophotometrically as described in Methodology. 
A

MCF-7 Cellular ATP

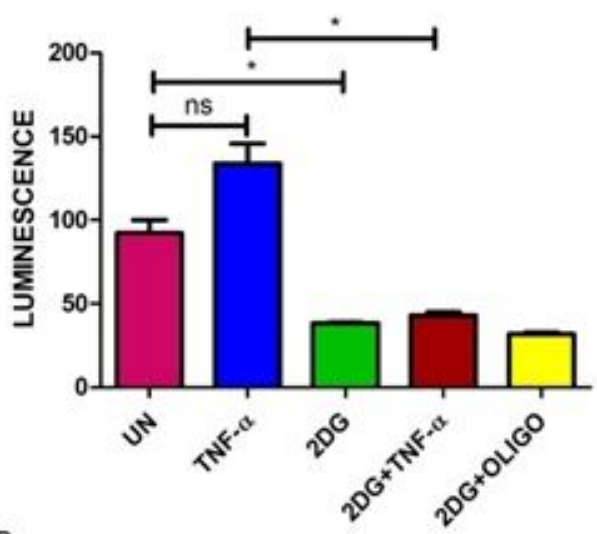

B

MCF-7 Mitochondrial ATP

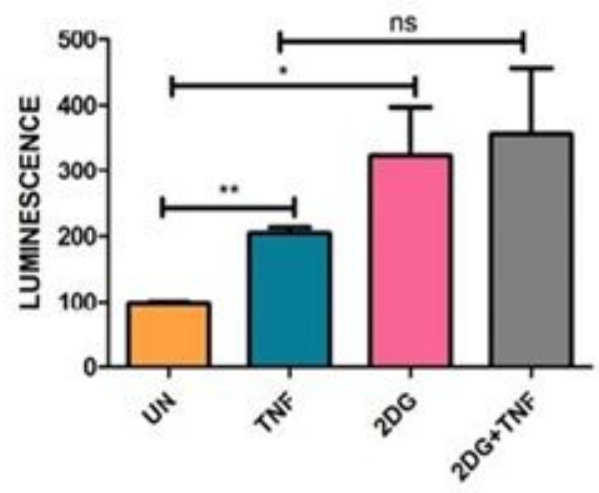

C

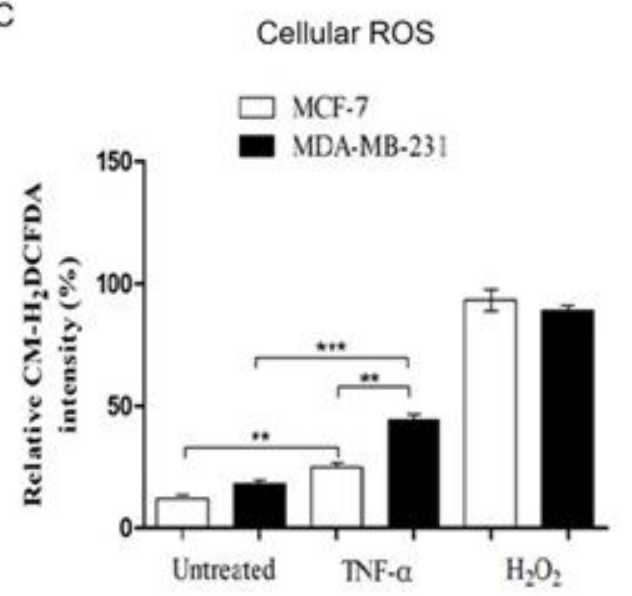

MDA-MB-231 Cellular ATP

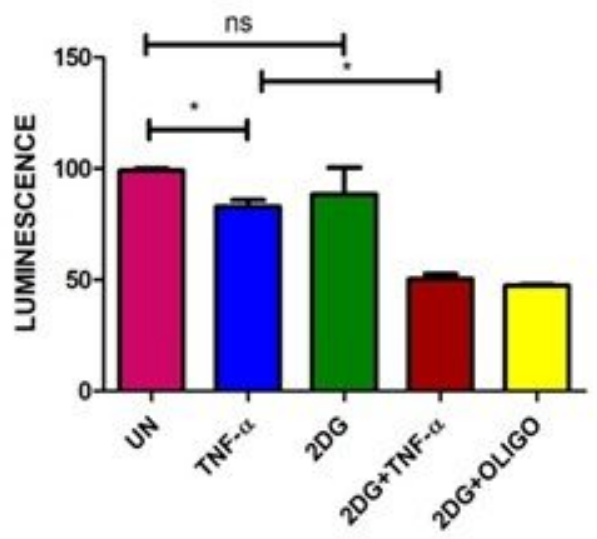

MDA-MB-231 Mitochondrial ATP

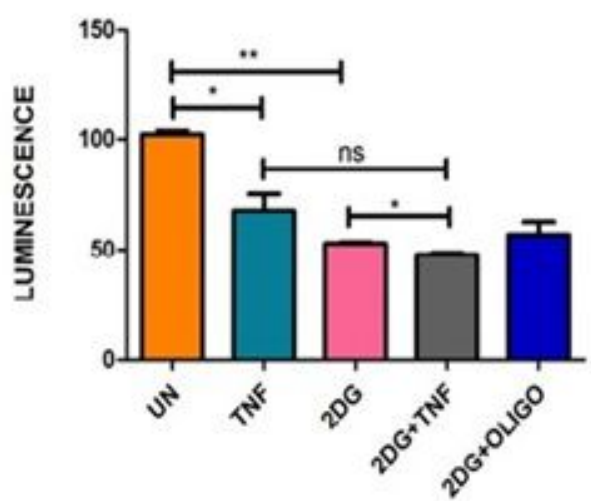

Mitochondrial ROS

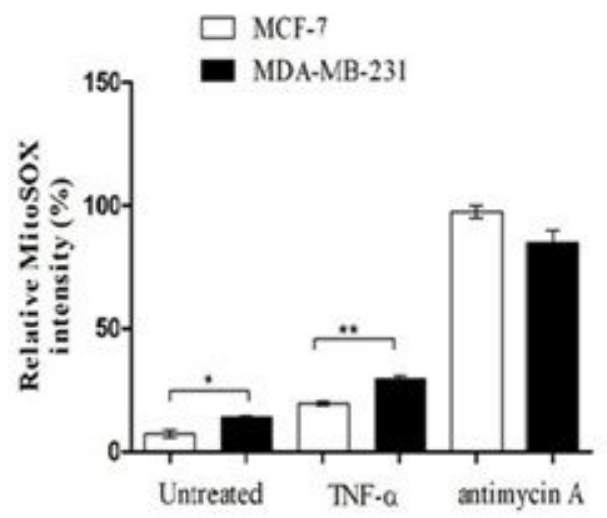

\section{Figure 4}

TNF-a decreases ATP levels and increases ROS generation in MDA-MB-231 cells. (A)MCF-7 and MDA-MB231 cells were treated with TNF-a wither alone or in combination with 2-DG (10 mM) and the total steadystate ATP levels were determined by luciferase-based assay as described in Methodology. (B) As in (A), mitochondria from respective cells were isolated upon treatment and ATP levels were measured. Oligomycin $(5 \mu \mathrm{g})$ treatment for 20 min was used as positive control. (C) MCF-7 and MDA-MB-231 cells 
were treated with TNF-a. After treatment, the cells were stationed with fluorogenic ROS-sensitive dye and relative fluorescence was monitored as described in Methodology. H2O2 (100 $\mu \mathrm{M})$ and antimycin A (10 $\mu \mathrm{g})$ treatment for $2 \mathrm{~h}$ were used as positive control.

A

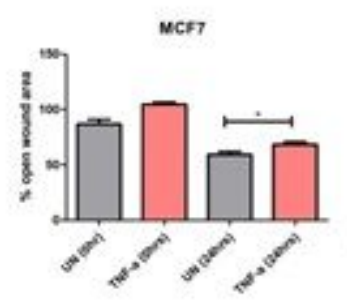

MDAM8.231

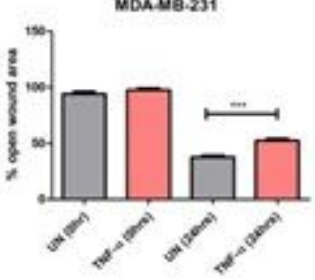

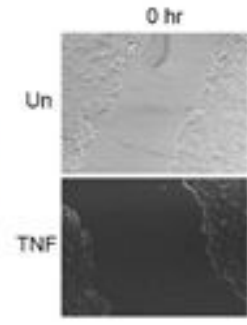

$0 \mathrm{hr}$

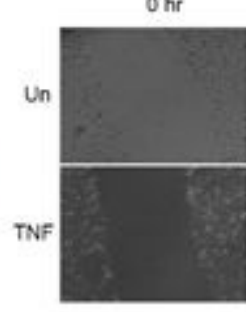

D

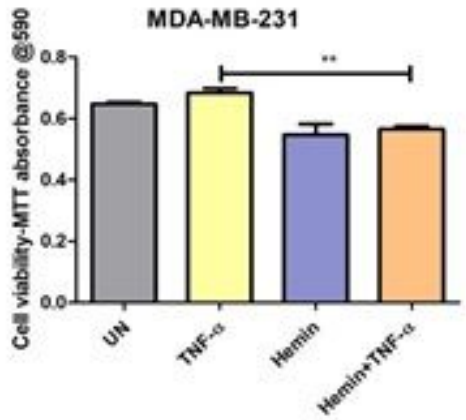

$24 \mathrm{hrs}$

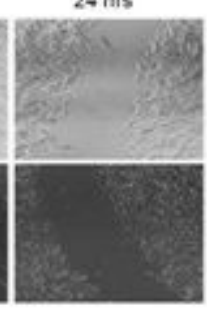

$24 \mathrm{hrs}$

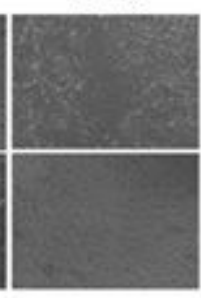

B
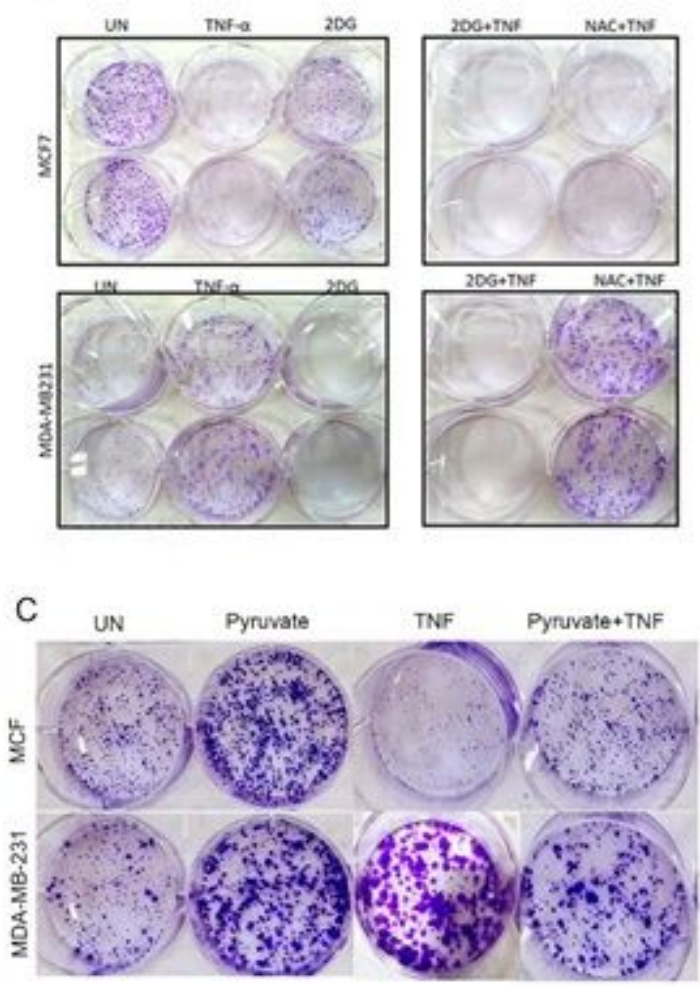

\section{Figure 5}

TNF-a sensitizes cell death and decreases growth in MDA-MB-231 cells negatively (A) MCF-7 and MDAMB-231 cells were seeded in 12 well plate \& wound scratch assay was performed in presence of TNF-a (B) \&(C) MCF-7 and MDA-MB-231 cells were seeded in low number as described in methodology and their ability to form colonies in the presence and absence of TNF-a,2-DG,NAC and pyruvate was monitored (D) MDA-MB-231 cells were treated with TNF-a either alone or in combination with Hemin $(10 \mathrm{mM})$ and the cell viability was assessed as described in Methodology by MTT. 
A
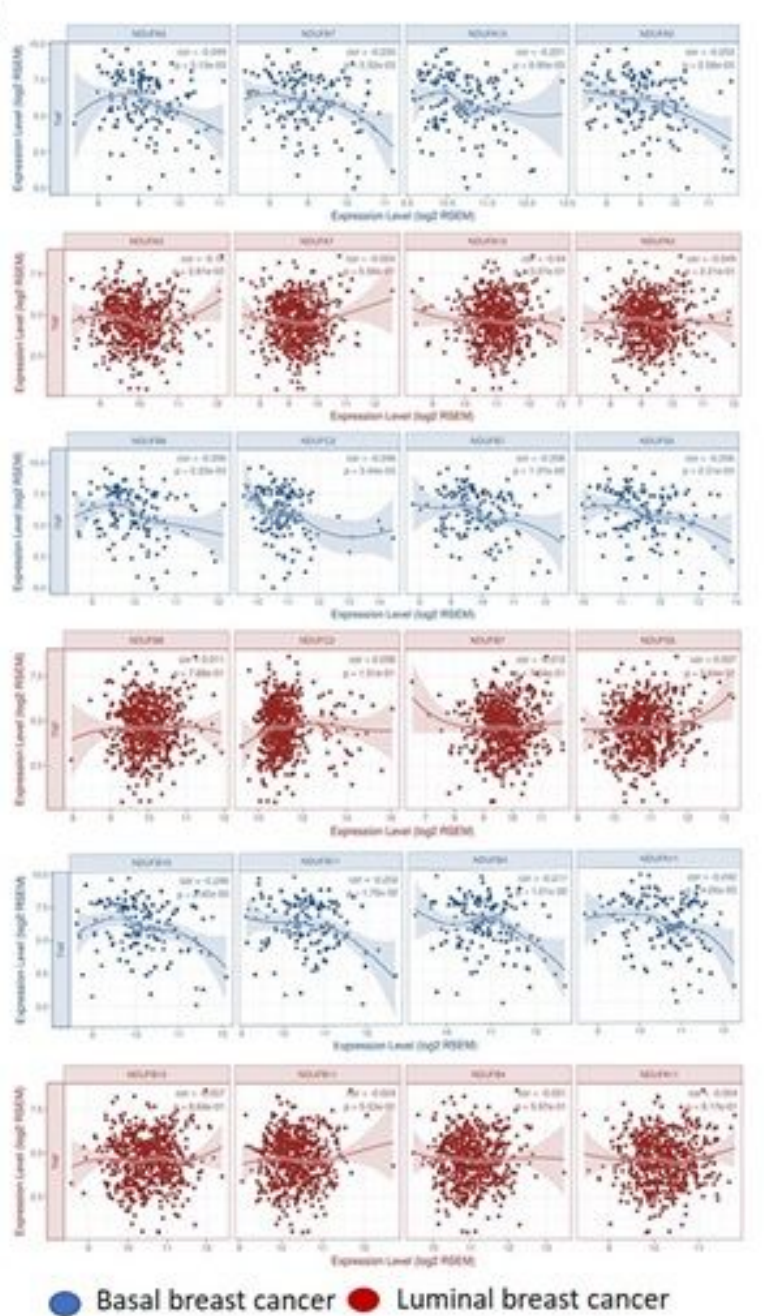

B
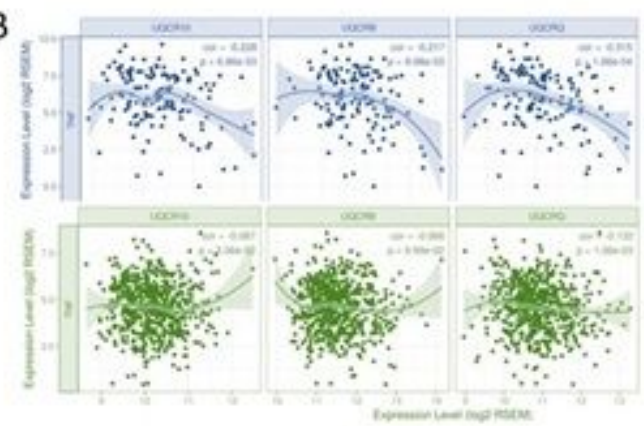

Basal breast cancer Luminal breast cancer

C
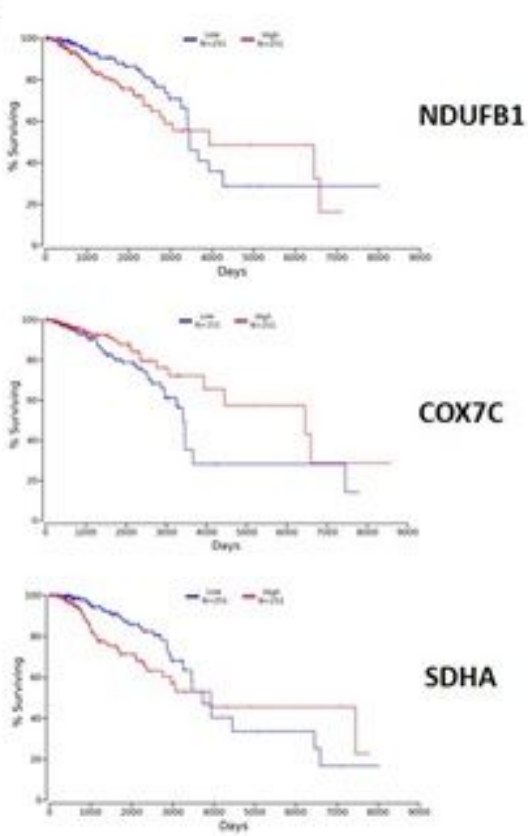

Figure 6

Subunit of complex negatively correlates with survival of the breast cancer patients (A)\& (B) Gene expression analysis between TNF- $a$ and mitochondrial Cland CIII proteinsusing TIMER database, respectively. Here orange indicates the gene expression in Basal and green indicates gene expression in Luminal breast cancer patients. (C) Kaplan Meier survival plot of BRCA patients in low/high expression of mitochondrial NDUFB1, COX7B and SDHA genes.

\section{Supplementary Files}

This is a list of supplementary files associated with this preprint. Click to download.

- FigureS1.jpg

- FigureS2.jpg 